\title{
Hot Potato: Characterising Pu particles from Maralinga, Australia
}

MEGAN COOK', BARBARA ETSCHMANN'*, RAHUL RAM', JOËL BRUGGER', KONSTANTIN IGNATYEV'2, GEDIMINAS GERVINSKAS', STEVEN CONRADSON ${ }^{3}$, SUSAN CUMBERLAND ${ }^{4}$, VANESSA NL WONG

${ }^{1}$ Monash University, Clayton 3800, Victoria, Australia.

* barbara.etschmann@monash.edu

${ }^{2}$ Diamond Light Source, Oxford, UK

${ }^{3}$ Washington State University, USA

${ }^{4}$ The University of Strathclyde, Glasgow, UK

The high-energy release of plutonium $(\mathrm{Pu})$ from a nuclear accident or weapon detonation results in its wide dispersion in the form of $\mu \mathrm{m}$-sized, highly radioactive 'hot' particles that persist in soils. We characterized the composition and textures of particles resulting from historical nuclear testing in Maralinga, Australia, from the micro- to the nano- scales, using a combination of synchrotron $\mu$ XANES, $\mu$ EXAFS, $\mu$ XRD, $\mu$ XRF, and fluorescence tomography combined with SEM. The hot particles show remarkably different physical/chemical characteristics. $\mathrm{Pu}$ and $\mathrm{U}$ are distributed relatively homogeneously in "Potatohead", and heterogeneously in "Bruce" (Figure 1). Pu exists as Pu(IV) in Potatohead, while the average oxidation state of $\mathrm{Pu}$ is $<\mathrm{IV}$ in Bruce; with a mix of U(IV/VI) in both. These particles originated from above ground, most likely subcritical tests, so their speciation may be different than that occurring from separations, research wastes or releases from reactors. The particles consist mainly of $\mathrm{Al}, \mathrm{Fe}$ and $\mathrm{Pb}$, materials from the bomb casing and/or test featherbeds.
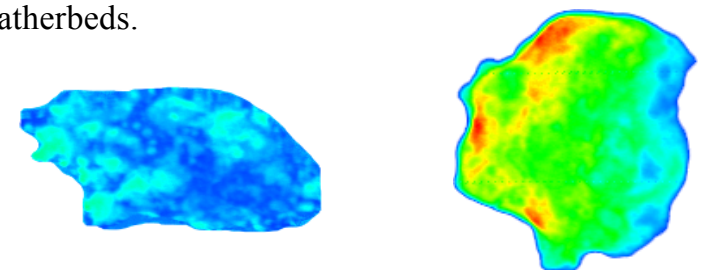

Figure 1: SXRF image of "Bruce" (left) highlighting the U/Pu variation within the particle, the lighter areas having more $U$ and SXRF image of Pu distribution in "Potatohead" (right). 